\title{
Analisa Kesehatan Reproduksi Remaja Perempuan Usia Early Adolescence di Pekanbaru
}

\author{
Oswati Hasanah ${ }^{a}$ Misrawati $^{a}$ \\ aprogram Studi Ilmu Keperawatan Universitas Riau \\ E-mail: unni_08@yahoo.com; misra_wati@yahoo.com
}

\begin{abstract}
The purpose of this study was to obtain reproductive health in adolescent girls in Pekanbaru. The design used was a simple descriptive with cross-sectional approach. 189 respondents were selected by random cluster sampling technique. The result showed that majority of respondents are in the early adolescence age (79.9\%) and most of them are Minangese (47.6\%). Based on the analysis related to breast health, the majority of respondents felt there is lump in their breast (80.4\%), but only $1.1 \%$ of them have ever attempted to enlarge the breasts. Most respondents (63\%) have good habits in clothing, but more than a half have physiological vaginal discharge $(55.6 \%)$, almost all respondents have unhealthy habits in toiletting (97\%) and ever tried to overcome the flour albus (94.7\%) with a variety of herbs using traditional ingredients (79 \%). It can be concluded in general the respondents still have a good reproductive health, but still required a sustained effort to maintain and improve the reproductive health status of adolescents in Pekanbaru.
\end{abstract}

Key words: adolescence, reproductive health

\begin{abstract}
Abstrak: Penelitian ini bertujuan untuk memperoleh gambaran kesehatan reproduksi pada remaja perempuan di Pekanbaru. Desain penelitian yang digunakan adalah deskriptif sederhana dengan teknik pengambilan data secara cross sectional. Sampel yang digunakan pada penelitian ini sebanyak 189 responden yang dipilih dengan teknik cluster random sampling. Dari hasil analisa didapatkan data sebagian besar responden berada pada usia early adolescence $(79,9 \%)$ dan sebagian besar bersuku minang $(47,6 \%)$. Berdasarkan analisa terkait kesehatan payudara, sebagian besar responden merasakan ada benjolan pada payudara $(80,4 \%)$, namun hanya $1,1 \%$ remaja yang pernah berupaya untuk memperbesar payudara. Sebagian besar responden (63\%) memiliki kebiasaan baik dalam memilih pakaian, namun lebih dari separuhnya mengalami keputihan $(55,6 \%)$ yang umumnya bersifat fisiologis, hampir seluruh responden memiliki kebiasaan cebok yang tidak sehat $(97 \%)$ dan pernah berusaha mengatasi keputihan (94,7\%) dengan aneka jamu dengan menggunakan ramuan tradisional (79\%). Dapat disimpulkan secara umum responden masih memiliki kesehatan reproduksi yang baik, namun masih diperlukan upaya yang berkelanjutan untuk dapat mempertahankan dan meningkatkan status kesehatan reproduksi remaja di Pekanbaru.
\end{abstract}

Kata $k u n c i$ : Remaja, Kesehatan reproduksi 


\section{PENDAHULUAN}

Masa remaja disebut juga sebagai masa pubertas, berada pada rentang usia 11 sampai dengan 20 tahun (Hockenberry \& Wilson, 2009). Pada masa ini terjadi transisi perkembangan antara periode kanak-kanak dan dewasa (Papalia, Old \& Feldman, 2008), selain itu juga terjadi pematangan cepat secara fisik, kognitif, sosial dan emosional (Hockenberry \& Wilson, 2009; Papalia, Old \& Feldman, 2008, 2008; Pillitteri, 1999). Kematangan organ reproduksi merupakan salah satu ciri kematangan fisik yang terjadi pada masa remaja.

Kematangan organ reproduksi hendaknya diikuti dengan kemampuan remaja untuk menjaga kesehatan organ reproduksinya. Menurut WHO (1948) kesehatan reproduksi adalah kesejahteraan fisik, mental dan sosial yang utuh dan bukan hanya tidak adanya penyakit atau kelemahan, dalam segala hal yang berhubungan dengan sistem reproduksi dan fungsi-fungsinya serta proses-prosesnya. pada remaja perempuan, organ reproduksi tidak hanya berfungsi untuk bereproduksi (prokreasi) saja, tapi sekaligus juga berfungsi sebagai organ seksual (rekreasi). Oleh karenanya kemapuan untuk menjaga kesehatan reproduksi secara mandiri menjadi hal yang mutlak harus dimiliki oleh remaja, dan ini sejalan dengan tugas perkembangan pada usia remaja.

Menurut Papalia, Old dan Feldman (2008) tugas perkembangan remaja diantaranya adalah kemampuan menerima citra tubuh, menerima identitas seksual, menerima sistem nilai personal, membuat persiapan untuk hidup mandiri, menjadi mandiri/bebas dari orangtua, mengembangkan keterampilan mengambil keputusan, dan mengembangkan identitas seorang dewasa. Akan tetapi seringkali pemahaman remaja terhadap tugas perkembangan yang harus dicapainya sering terhambat, seringkali ini disebabkan oleh banyaknya masalah yang tidak dapat mereka atasi sendiri. Masalah tersebut dapat bersifat patologis maupun fisiologis akibat peningkatan produksi berbagai hormon dalam tubuhnya.

Perubahan secara fisik pada organ reproduksi di masa remaja dipengaruhi oleh pematangan hormon seksual. Pada remaja perempuan terjadi peningkatan hormon estrogen dan progesteron menyebabkan perubahan seks sekunder diantaranya perubahan postur tubuh, pembesaran payudara, pertumbuhan rambut kelamin dan aksila serta mulai terjadi menstruasi (Hockenberry \& Wilson, 2009). Perubahan yang bersifat fisiologis ini dapat menjadi masalah bagi remaja, terutama karena kurangnya pemahaman terhadap mekanisme alamiah dalam diri mereka. Masalah fisik yang sering dihadapi diantaranya adalah payudara yang mulai membesar dan terasa bengkak, dismenore, keputihan, gatal dan rasa tidak nyaman pada alat kelamin hingga infeksi pada saluran kemih akibat kurang pengetahuan dalam menjaga kebersihan alat kelamin.

Selain perubahan fisik pada usia remaja juga terjadi juga terhadi perubahan psikologis, diantaranya mudah emosi, lebih mementingkan kelompok sebaya daripada keluarga dan ketertarikan dengan lawan jenis (Papalia, 2008). Kondisi ini dapat meningkatkan perilaku remaja ke arah baik, jika remaja mendapatkan pengarahan yang tepat dari sumber yang tepat. Perubahan ini juga sering meningkatkan perilaku negatif akibat dari pengaruh teman sebaya dan kurangnya pengetahuan terhadap dampak perilaku tersebut. Pemahaman yang baik dapat didukung oleh support sistem yang baik dari keluarga maupun guru di sekolah.

Berdasarkan data yang didapatkan dari hasil penelitian oleh tim departeman maternitas PSIK Universitas Riau tahun 2011, sebanyak 40\% masalah kesehatan reproduksi di Pekanbaru terjadi pada perempuan (dewasa dan remaja). Pada remaja perempuan, kondisi ini tentunya akan berdampak pada kualitas kesehatan fisik dan mental pada usia dewasa nanti. Untuk mencegah dampak negatif dari kondisi ini, perlu dilakukan deteksi dini pada remaja perempuan terkait kesehatan reproduksinya 
agar dapat segera dilakukan penatalaksanaan yang tepat. Beradasarkan fenomena tersebut, maka peneliti tertarik untuk meneliti tentang deskripsi kesehatan reproduksi remaja di Pekanbaru. Tujuan dari penelitian ini adalah untuk mendapatkan gambaran secara rinci tentang kesehatan reproduksi remaja perempuan di area pinggiran kota Pekanbaru.

\section{METODE}

Penelitian ini penggunakan desain penelitian deskriptif sederhana dengan pendekatan cross sectional. Populasi pada penelitian ini adalah seluruh remaja perempuan yang bersekolah di 3 SMP di kecamatan Rumbai Pekanbaru, dengan jumlah responden sebanyak 189 orang yang dipilih secara acak dengan teknik cluster Random Sampling dan sudah memenuhi kriteria inklusi sebagai berikut: siswi kelas 7 dan 8, Sudah mengalami menstruasi, dan bersedia menjadi responden dalam penelitian.

Pengumpulan data dilakukan dengan dengan menggunakan kuesioner yang berisikan pertanyaan tentang data demografi dan 15 pertanyaan/pernyataan terkait kesehatan reproduksi perempuan yang berhubungan dengan kesehatan payudara dan organ kelamin. Pertanyaan yang diajukan berupa pertanyaan tertutup dengan pilihan jawaban Ya dan Tidak untuk tiaptiap pertanyaan.

\section{HASIL DAN PEMBAHASAN}

Penelitian dilakukan pada bulan Mei Juli 2012 pada 3 sekolah menengah pertama di kecamatan Rumbai, kota Pekanbaru. Karakteristik responden dilihat dari kategori usia dan suku dapat dilihat pada tabel 1 .

Tabel 1. Distribusi responden berdasarkan usia dan suku

\begin{tabular}{lcc}
\hline \multicolumn{1}{c}{ Karakteristik } & Frekuensi & \% \\
\hline $\begin{array}{l}\text { Usia } \\
\text { - Early } \\
\text { adolescence } \\
(12-14)\end{array}$ & 151 & 79,9
\end{tabular}

\begin{tabular}{lrc}
$\begin{array}{l}\text { - Middle } \\
\text { adolescence } \\
(15-17)\end{array}$ & 38 & 20,1 \\
\hline$\quad$ Suku & & \\
- Minang & 90 & 47,6 \\
- Melayu & 43 & 22,8 \\
- Jawa & 26 & 13,8 \\
- Batak & 21 & 11,1 \\
- Lain-lain & 9 & 4,76 \\
\hline
\end{tabular}

Dari 189 orang responden, sebagian besar merupakan remaja usia early adolescence (79,9\%). Kategori usia ini secara umum adalah remaja yang duduk di kelas 7 dan 8 di sekolah menengah pertama. Sesuai dengan kriteria pemilihan responden. Pengkategorian usia respinden pada tabel 1 didasarkan pada kategori usia remaja menurut Santrock (2007), ia menggolongkan remaja usia awal adalah usia 12-14 tahun dan remaja usia pertengahan ada pada rentang 15-17 tahun.

Berdasarkan hasil analisa terhadap suku, sebagian besar responden bersuku minang $(47,6 \%)$ dan melayu $(22,8 \%)$, sisanya adalah suku jawa, batak, dan-lainlain. Pekanbaru merupakan kota dengan dengan mayoritas penduduk bersuku Melayu. Di sisi lain Pekanbaru merupakan daerah berdekatan dengan propinsi Sumatera Barat yang bersuku Minang. Hampir sebagian masyarakat di Pekanbaru menggunakan bahasa Minang dalam berinteraksi. Lebih banyaknya responden yang bersuku Minang tidaklah menggambarkan komposisi penduduk kota Pekanbaru secara keseluruhan, namun hanya merupakan kebetulan saja dalam pemilihan responden pada penelitian ini, dan dapat dijadikan sumber informasi keberagaman latarbelakang budaya remaja di kota Pekanbaru. Gambaran analisa distribusi terhadap kesehatan reproduksi remaja perempuan dapat dilihat secara rinci pada tabel 2. Berdasarkan struktur pertanyaan, daftar pertanyaan terdiri dari 2 kategori, yaitu pertanyaan tentang kesehatan payudara dan kesehatan organ genitalia. Daftar pertanyaan tentang kesehatan payudara hanya terdiri dari 2 pertanyaan, jauh lebih 
sedikit dibandingkan 12 pertanyaan terkait dengan kesehatan organ genitalia. Kesehatan reproduksi terutama pada organ genitalia pada masa remaja merupakan penting baik bagi laki-laki dan perempuan, pada usia ini organ reproduksinya mulai berfungsi aktif (Hockenberry \& Wilson, 2009).

Tabel 2. Distribusi responden berdasarkan deskripsi kesehatan kesehatan reproduksi.

\begin{tabular}{|c|c|c|c|c|c|}
\hline \multirow{2}{*}{$\begin{array}{l}\mathbf{N} \\
\mathbf{O}\end{array}$} & \multirow{2}{*}{$\begin{array}{c}\text { PERTANYAA } \\
\mathbf{N} \\
\end{array}$} & \multicolumn{2}{|c|}{ YA } & \multicolumn{2}{|c|}{ TIDAK } \\
\hline & & $\mathbf{f}$ & $\%$ & f & $\%$ \\
\hline & $\begin{array}{l}\text { Status } \\
\text { kesehatan } \\
\text { payudara }\end{array}$ & & & & \\
\hline 1 & $\begin{array}{l}\text { Ada benjolan } \\
\text { pada payudara }\end{array}$ & 37 & $\begin{array}{c}19 \\
6\end{array}$ & 152 & 80,4 \\
\hline 2 & $\begin{array}{l}\text { Pernah } \\
\text { menggunakan } \\
\text { obat-obatan } \\
\text { pembesar } \\
\text { payudara }\end{array}$ & 2 & 1,1 & 187 & 98,9 \\
\hline & $\begin{array}{l}\text { Status } \\
\text { kesehatan } \\
\text { organ } \\
\text { genitalia }\end{array}$ & & & & \\
\hline 3 & $\begin{array}{l}\text { Suka memakai } \\
\text { celana ketat }\end{array}$ & 70 & 37 & 119 & 63 \\
\hline 4 & $\begin{array}{lr}\text { Ada lecet/luka } \\
\text { pada } & \text { alat } \\
\text { kelamin } & \end{array}$ & 8 & 4,2 & 181 & 95,8 \\
\hline 5 & $\begin{array}{l}\text { Ada nyeri saat } \\
\text { pipis }\end{array}$ & 8 & 4,2 & 181 & 95,8 \\
\hline 6 & $\begin{array}{l}\text { Cebok dengan } \\
\text { cara } \\
\text { mengusap/men } \\
\text { yiram air dari } \\
\text { belakang ke } \\
\text { depan }\end{array}$ & 92 & $\begin{array}{c}48, \\
7\end{array}$ & 97 & 51,3 \\
\hline 7 & $\begin{array}{l}\text { Mengeringkan } \\
\text { kelamin dengan } \\
\text { kain/tisue } \\
\text { setelah cebok }\end{array}$ & 70 & 37 & 119 & 63,0 \\
\hline 8 & $\begin{array}{l}\text { Memakai obat } \\
\text { pembersih } \\
\text { organ } \\
\text { kewanitaan }\end{array}$ & 42 & $\begin{array}{c}22, \\
2\end{array}$ & 147 & 77,8 \\
\hline 9 & \begin{tabular}{ll}
\multicolumn{2}{l}{ Pernah } \\
menggunakan \\
rebusan daun \\
sirih $\quad$ untuk
\end{tabular} & 39 & $\begin{array}{c}20, \\
6\end{array}$ & 150 & 79,4 \\
\hline
\end{tabular}

\begin{tabular}{|c|l|c|c|c|c|}
\hline & cebok & & & & \\
\hline 10 & $\begin{array}{l}\text { Memakai } \\
\text { pantiliner/pem- } \\
\text { balut saat tidak } \\
\text { menstruasi bila } \\
\text { pergi sekolah }\end{array}$ & 27 & $\begin{array}{c}14, \\
3\end{array}$ & 162 & 85,7 \\
\hline 11 & $\begin{array}{l}\text { Saat ini } \\
\text { mengalami } \\
\text { keputihan }\end{array}$ & 84 & $\begin{array}{c}44, \\
4\end{array}$ & 105 & 55,6 \\
\hline 12 & $\begin{array}{l}\text { Keputihan } \\
\text { terasa gatal }\end{array}$ & 31 & $\begin{array}{c}16, \\
4\end{array}$ & 158 & 83,6 \\
\hline 13 & $\begin{array}{l}\text { Keputihan } \\
\text { berbau tidak } \\
\text { sedap 49 }\end{array}$ & $\begin{array}{c}25, \\
9\end{array}$ & 140 & 74,1 \\
\hline 14 & $\begin{array}{l}\text { Pernah minum } \\
\text { jamu saat } \\
\text { keputihan }\end{array}$ & $\begin{array}{l}17 \\
9\end{array}$ & 7 & 10 & 5,3 \\
\hline
\end{tabular}

Data Deskripsi kesehatan reproduksi didapatkan dari kuesioner yang berbentuk pertanyaan, namun pada tabel 2, tampilan data adalah dalam bentuk pernyataan. Pada item pertanyaan tentang adanya benjolan pada payudara, sebagian besar responden $(80,4 \%)$ menjawab ya. Benjolan pada payudara dapat mengarah pada keganasan, misalnya Fibrosa Adeno Mamae (FAM) yang sering dialami oleh remaja perempuan. Akan tetapi diagnosis FAM tidak dapat ditegakkan hanya dengan mengandalkan pemeriksaan fisik saja, masih memerlukan diagnosa lebih lanjut. Kemungkinan lainnya, benjolan tersebut merupakan proses perkembangan ductus mamae menghingat sebagian besar responden masih berada pada usia early adolescence, yang akan terus berlanjut hingga usia remaja akhir.

Kebiasaan baik dalam memelihara kesehatan payudara ditunjukkan dari jumlah remaja yang mencoba memperbesar payudara dengan obat-obatan tertentu hanya berjumlah sebanyak 1, 1\% saja dari total responden. Pada usia remaja wajar ada rasa ingin tahu dan penasaran ingin mencoba sesuatu yang baru sebagai upaya untuk memiliki tubuh yang ideal. Ukuran payudara merupakan bagian penting bagi sebagian remaja perempuan untuk menumbuhkan body image yang positif dalam pergaulan. Kemungkinan keinginan dan upaya untuk memiliki ukuran payudara yang ideal akan 
lebih meningkat pada remaja usia late adolescence.

Terkait kesehatan organ genitalia, mayoritas responden (63\%) memiliki kebiasaan baik dalam pemilihan penggunaan pakaian. Hanya $37 \%$ responden yang memiliki kebiasaan penggunaan celana yang ketat. Mode berpakaian dan fashion merupakan hal yang penting bagi remaja untuk membentuk citra tubuh dan dianggap dapat mempengaruhi pergaulan. Perasaan diterima oleh teman sebaya akan menimbulkan perasaan bangga dan merupakan aspek penting di usia pubertas (Santrock, 2007), namun kebiasaan menggunakan celana yang ketat dalam waktu lama juga dapat menimbulkan dampak negatif yang sering tidak disadari oleh remaja.

Beberapa dampak yang dapat ditimbulkan oleh kebiasaan menggunakan celana yang terlalu antara lain infeksi saluran kemih (ISK) baik oleh bakteri ataupun jamur. Kondisi ini dapat bermanifestasi dengan adanya keluhan nyeri saat berkemih, bahkan juga keputihan. Keputihan yang berasifat patologis dan infeksi dapat menimbulkan rasa gatal, jika digaruk maupun tergaruk akan menimbulkan luka/lecet. Area yang luka dan lecet ini kemudian dapat menjadi sumber infeksi skunder di sekitar alat kelamin. Dari hasil analisa ditemukan hanya sebagian kecil responden saja yang mengalami luka/lecet pada alat kelamin $(4,2 \%)$, maupun yang merasakan nyeri saat buang air kecil $(4,2 \%)$. Meskipun lebih dari separuh responden $(55,6 \%)$ mengalami keputihan namun hanya sebagian kecil responden yang mengalami ciri keputihan yang bersifat patologis dengan manifesasi gatal $(16,4 \%)$ dan berbau tidak sedap $(25,9 \%)$. Sebagian besar responden mengalami keputihan yang bersifat fisiologis.

Masalah pada organ genitalia pada sebagian kecil responden dapat juga disebabkan karena faktor lain, misalnya higiene yang kurang baik. Ini dapat terlihat dari data sebagian besar responden $(97 \%)$ terbiasa menggunakan cara yang salah untuk membersihkan organ genitalia. Teknik membersihkan organ genitalia yang paling aman setelah selesai buang air adalah dengan menyiram air/cebok dari depan ke belakang. Namun sebagian besar responden melakukan sebaliknya. Penyiraman dari arah dubur akan ikut membawa kuman patogen dari dubur ke organ genitalia. Jika remaja juga memiliki kebiasaan yang buruk degan membiarkan organ tersebut dalam keadaan lembab, baik karena kebiasaan menggunakan pakaian yang ketat, penggunaan pembalut kewanitaan yang salah, maupun tidak mengeringkan area tersebut setelah cebok, area tersebut akan menjadi area yang kondusif untuk perkembangan biakan bakteri dan jamur. Analisa menunjukkan sebagian besar remaja sudah memiliki kebiasaan untuk mengeringkan area genitalia setelah buang air (63\%) dan tidak menggunakan pembalut/pentiliner saat tidak menstruasi $(85,7 \%)$, ini merupakan kebiasaan yang baik.

Pada usia remaja awal sudah mulai terbentuk prilaku mandiri untuk meningkatkan kesehatan diri (health seeking behaviour), kesadaran ini mulai muncul, seiring dengan perkembangan aspek kognitif pada remaja (Santrock, 2007). Hanya saja upaya ini perlu mendapat dukungan dan pantauan dari support sistem yang ada, misalnya dari orang tua, keluarga dan guru, agar perilaku dapat mengarah pada kebiasaan yang baik. Health seeking behaviour pada responden dalam penelitian ini ditunjukkan dengan upaya remaja untuk mengatasi keputihan, dimana hampir seluruh responden $(94,7 \%)$ pernah meminum jamu untuk mengatasi keputihan. Pada penelitian ini tidak ditanyakan jenis jamu maupun pengobatan yang menjadi alternatif pilihan remaja. Sebagian besar remaja tergambar lebih memilih penggunaan ramuan tradisional untuk membersihkan organ genitalia (79\%) dengan menggunakan rebusan daun sirih.

Pilihan penggunaan obat-obatan tradisional untuk mengatasi masalah pada 
alat genitalia juga dapat dipengaruhi oleh faktor kebiasaan yang ditiru dalam keluarga dan ketersedian ramuan tersebut secara luas di sekitar tempat tinggalnya. Kemungkinan responden terpapar oleh promosi media massa untuk meningkatkan kesehatan organ reproduksi mungkin dapat digambarkan oleh data yang menunjukkan sebagian kecil remaja $(22,2 \%)$ pernah memakai obat pembersih organ kewanitaan yang dijual secara komersil dan tersedia di warung-warung yang gampang diakses oleh remaja. Penggunaan bahan kimia pada organ genitalia dalam waktu lama dan dengan cara yang salah dapat membahayakan kesehatan organ reproduksi remaja, oleh karena itu penting bagi remaja untuk mendapatkan arahan yang tepat dari berbagai support sistem yang ada.

Banyak perubahan yang terjadi pada remaja pada masa pubertas, baik secara fisik maupun psikologis. Perubahan yang berlangsung pada masa pubertas ini awalnya merupakan peristiwa yang membingungkan bagi remaja (Barker,2007). Meskipun pada akhirnya remaja dapat mengatasinya, perubahan ini pada awalnya menimbulkan keraguraguan, ketakutan dan kecemasan secara terus menerus (Santrock, 2007). Oleh karenanya di usia remaja awal dan pertengan, remaja masih berpotensi untuk mendapatkan pengaruh negatif dari lingkungannya terkait kesehatan reproduksinya. Untuk menghindari hal tersebut, remaja memerlukan pendampingan dan pengawasan dari sekolah, guru, keluarga dan masyarakat agar mereka apat mempertahankan status kesehatan reproduksinya hingga usia dewasa nantinya.

\section{KESIMPULAN DAN SARAN.}

Dari hasil penelitian dapat disimpulkan bahwa sebagian besar responden memiliki kesehatan reproduksi yang baik. Namun demikian karena remaja usia ini masih perada pada tahap perkembangan yang labil dan mudah terpengaruh oleh lingkungan dan teman sebayanya, maka remaja usia ini masih berpotensi untuk mengalami kesehatan reproduksi yang buruk di masa mendatang. Untuk menghindari kemungkian tersebut dan untuk mempertahankan status kesehatan reproduksi yang baik pada remaja ini dibutuhkan perhatian dari semua support sistem, baik dari sekolah, guru, orang tua, masyarakat, maupun pelayanan kesehatan.

Pihak sekolah diharapkan dapat memfasilitasi siswa/siswi untuk dapat memperoleh informasi tentang kesehatan reproduksi melalui berbagai sumber belajar yang sehat dan terpercaya. Para guru dapat menyisipkan informasi tentang kesehatan organ reproduksi pada mata pelajaran yang berkaitan maupun pada kegiatan ekstrakurikuler. Pelayanan kesehatan baik rumah sakit maupun puskesmas diharapkan dapat mengembangkan program terpadu yang bersifat adolescence friendly khususnya terkait kesehatan reproduksi. Kegiatan penelitian lanjutan dapat diarahkan untuk menggali lebih dalam aspek-aspek kesehatan reproduksi remaja yang terkait dengan berbagai budaya di Indonesia.

\section{DAFTAR PUSTAKA}

Barker, G. (2007) Adolescents, social support and help-seeking behaviour, an international literature review and programme consultation with recommendations for action. Geneva: WHO Library Cataloguing-inPublication Data.

Hockenberry, M. J. \& Wilson D. (2009). Wong's essentials of pediatric nursing, eighth edition. St Louis, Missouri: Mosby.

Papalia, D. E., Old, S. W. \& Feldman, R. D. (2008). Human development. Jakarta: Kencana Prenada Gramedia Group.

Pillitteri, A. (1999). Child health nursing. care of the child and family. Philadelphia : Lippincott.

Santrock, J. W. (2007). Remaja, edisi 11, jilid 1. Jakarta: Erlangga. 